Article

\title{
Gender Differences in Tackling Fake News: Different Degrees of Concern, but Same Problems
}

\author{
Ester Almenar *, Sue Aran-Ramspott, Jaume Suau and Pere Masip \\ Blanquerna School of Communication and International Relations, Ramon Llull University, 08001 Barcelona, Spain; \\ E-Mails: esteraat1@blanquerna.url.edu (E.A.), suear@blanquerna.url.edu (S.A.-R), jaumesm@blanquerna.url.edu (J.S.), \\ peremm@blanquerna.url.edu (P.M.)
}

* Corresponding author

Submitted: 30 July 2020 | Accepted: 11 September 2020 | Published: 3 March 2021

\begin{abstract}
In the current media ecosystem, in which the traditional media coexists with new players who are able to produce information and spread it widely, there is growing concern about the increasing prominence of fake news. Despite some significant efforts to determine the effects of misinformation, the results are so far inconclusive. Previous research has sought to analyze how the public perceive the effects of disinformation. This article is set in this context, and its main objective is to investigate users' perception of fake news, as well as identify the criteria on which their recognition strategies are based. The research pays particular attention to determining whether there are gender differences in the concern about the effects of fake news, the degree of difficulty in detecting fake news and the most common topics it covers. The results are based on the analysis of a representative survey of the Spanish population ( $N=1,001)$ where participants were asked about their relationship with fake news and their competence in determining the veracity of the information, and their ability to identify false content were assessed. The findings show that men and women's perception of difficulty in identifying fake news is similar, while women are more concerned than men about the pernicious effects of misinformation on society. Gender differences are also found in the topics of the false information received. A greater proportion of men receive false news on political issues, while women tend to more frequently receive fake news about celebrities.
\end{abstract}

\section{Keywords}

disinformation; fake news; gender; misinformation; perception; Spain

\section{Issue}

This article is part of the issue "Disinformation and Democracy: Media Strategies and Audience Attitudes" edited by Pere Masip (University Ramon Llull, Spain), Bella Palomo (University of Málaga, Spain) and Guillermo López (University of Valencia, Spain).

(C) 2021 by the authors; licensee Cogitatio (Lisbon, Portugal). This article is licensed under a Creative Commons Attribution 4.0 International License (CC BY).

\section{Introduction}

The relationship between screens and their influence on individuals has been further complicated by the emergence of digital platforms. In the current media ecosystem, in which the traditional media coexist alongside new media and also new players who are capable of producing information and spreading it widely, there is a growing concern about the increasing prominence of fake news. Despite some significant efforts to determine the effects of disinformation, the results are inconclusive, and there are many research gaps which have still to be addressed (Tucker et al., 2018). More specifically, recent research has addressed the consequences of exposure to disinformation in different societal groups or individuals with diverse characteristics. For example, fake news has been studied in relation to political beliefs or ideology (Allcott \& Gentzkow, 2017; Guess, Nagler, \& Tucker, 2019), news consumption or social media use (Wagner \& Boczkowski, 2019) or national feelings (Khaldarova 
\& Pantti, 2016). Although studies of the reception of fake news are still at an early stage (Jankowski, 2018), we have identified a clear absence of a gender-based approach to the topic. Issues of gender have been taken into account in relation to fake news but normally from a perspective based on the content or message analysis (Stabile, Grant, Purohit, \& Harris, 2019) or the strategies of far-right groups in what has been defined as cultural wars (Mudde, 2019). As will be further explained in the literature review section, this article draws on reception studies on the dimension of gender differences in news consumption (Fortunati, Deuze, \& de Luca, 2014; Toff \& Palmer, 2019) as well as the previously identified gender attitudinal differences with regard to the use of new communication technologies (Bond, 2009; Cai, Fan, \& Du, 2017; Renau, Carbonell, \& Oberst, 2012). From this theoretical basis, this article aims to investigate whether there are gender differences in the users' perception of fake news. More specifically, we will focus on several issues which have already been researched in connection with fake news, but where the gender dimension has been normally disregarded. These include concerns about the spread of fake news, the degree of difficulty in detecting it and the topics received.

Although authors like Wardle and Derakhshan (2017) distinguish between misinformation, disinformation and mal-information, and it is well known that the use of the term 'fake news' is problematic, for the purpose of this article we will use the terms disinformation and fake news interchangeably, particularly in the results section. Scholars tend to avoid using the term 'fake news' because they consider that it is inadequate to describe the complex phenomena of false information (Tandoc, Lim, \& Ling, 2018). However, for ordinary people, fake news is the most popular and frequently used expression to refer to the nebula of false information, viral lies, conspiracy theories, and other forms of misleading information spread on social networks and some news media (in Spanish, notícias falsas). Since the research is based on a survey of a representative sample of the Spanish population, we decided to use the most familiar word in order to avoid misunderstanding.

\section{Reception Studies, Disinformation and the Gender Dimension}

From a theoretical perspective, Audience Reception Studies could help us to investigate individual's perceptions and understanding of disinformation from a gender perspective. Reception studies began in the 1980 s as a reaction to the widespread assumption that the audience was 'passive' in its media consumption, portraying audiences as easy to manipulate and homogeneous in their behavior and characteristics (Livingstone, 1998). Reception studies implied a change in viewing audiences as heterogeneous and resistant in their media consumption. Hence, audiences were then defined both by their personal characteristics as well as by their social contexts
(Mattelart \& Neveu, 2003). Since the 1980s reception studies have evolved and adapted to an ever-changing media system. Nowadays the new view of the audience as 'active' is highly relevant, thanks to the possibilities of the new communication technologies, which allow greater user interactivity with media content (Banaji \& Buckingham, 2013; Jenkins, 2006; Jenkins \& Carpentier, 2013; Scolari, 2012).

In principle, misleading content is not considered as a gender-specific media product. However, rather than conceptualizing audiences as passive consumers, or victims of this content, we suggest that we should conceptualize them as active in that they could challenge or re-appropriate the content. In this sense, it would be relevant to analyze whether gender plays a role in how individuals receive and react to fake news. Re-appropriation must always be considered within the context of the social situation in which it takes place as well as within the routines of everyday life and personal characteristics, which are so important at the beginning of the feminist audience studies according to Cavalcante, Press, and Sender (2017). Even before the digital hybrid media system (Chadwick, 2013), audience research stresses the importance of media consumption patterns in everyday life (Bird, 2003; Morley, 1992) as well as the social and relational roles in which this consumption takes place (Boczkowski, 2010). The gender approach is very relevant in these areas of research. Previous research showed significant differences in how women and men find and consume news, as well as the topics that most interest them (Fortunati et al., 2014). It seems that women may be more interested in news and reporting which is directly related to daily life, such as the weather, health and similar topics, and less interested in 'hard' political news (Poindexter \& Harp, 2008). A 'news consumption gender gap' has also been identified (Toff \& Palmer, 2019) that plays an important role in shaping how women consume less news through patterns of news avoidance, news-is-for-men perceptions and structural inequalities that shape individuals' everyday media consumption habits.

It seems then, that with regard to news' consumption, there are substantial differences between genders, affecting which types of news are more or less consumed by both women and men. Previous research has addressed the issue of topics of disinformation, but disregarded the gender differences. There is broad agreement that disinformation has a strong political component, linked to partisanship and identity politics (Mourão \& Robertson, 2019). Hence, a high proportion of fake news relates to such topics and narratives. However, researchers have also found differences between countries, with regard to specific national political issues, divisions or media system characteristics. For example, Humprecht (2019) found great differences in comparing the US and UK with Germany and Austria. While the former have a higher level of partisan-based disinformation content, in German-speaking countries 
sensationalist stories are more prominent. Hence, disinformation mirrors national news agendas and political debates. Furthermore, contextual events could also modify which types of fake news are most frequently consumed. For example, the outbreak of Covid-19 implied that disinformation about health issues became more relevant and widespread, as recent research in Spain shows (Masip et al., 2020; Salaverría et al., 2020). Despite these interesting patterns, the gender aspect has not been fully addressed. Hence, our first research question will be to see if the previously identified 'news consumption gender gap' can be extended to fake news reception:

RQ1: Are there gender differences in the perceptions of the most common topics of fake news that are received?

However, the 'news consumption gender gap' is not the only gender bias found by previous research. As Cai et al. (2017) point out, as regards the new communication technologies, there still exists a gender attitudinal gap as a consequence of many different factors, including the general conception that technology is a male-dominated area, that men are more competent users of technology, and other social and cultural norms and factors. This leads to many different relationships with digital news content between men and women. As Bond (2009) highlights, the two genders exhibit different motivations for engaging in social media use, a feature that can be explained through behavioural patterns of socialization (Renau et al., 2012). As Toff and Palmer (2019, p. 1565) observe: "According to the theories of socialization, gender roles and news consumption habits tend to originate in the home and are reinforced and modeled in school, among peers, and in the media." As previous research has emphasized, the approach to news media has gender differences. This goes further than the gender preferences on the volume, content and topics or the ways to find news, to the socialization processes, modeled from childhood and reinforced by, among other agents, the media system, and includes a structural inequality. This structural difference seems to be more of a historical constant than an anomaly and implies what has been defined as 'cognitive costs': If we consider that women are, in general, less educated, especially about political matters, the 'cognitive costs' of deciphering and focusing on politics might be higher (Benesch, 2012). Hence, if media consumption and use of technology are so strongly influenced by gender-related issues, we believe that it is pertinent that audience researchers pay attention to the possible gender-based media perception with regard to the criteria of trust in the digital field.

One interesting issue, therefore, is how these 'cognitive costs' might relate firstly to the capacity of individuals to be concerned about disinformation, firstly, and secondly to detecting this kind of content. Can we talk about the different cognitive costs between women and men regarding the capacity to detect fake news?
Does the lack of interest in political news make women less likely to be worried about the spread of misleading content? Existing research on disinformation has not fully addressed this a gender approach, with just a few exceptions (Ştefăniţă, Corbu, \& Buturoiu, 2018). When researching fake news, it has been found that individuals do not clearly distinguish such content from news, although the results are better if they need to identify propaganda or advertising (Nielsen \& Graves, 2017). It seems that for many individuals, fake news might be synonymous with 'bad journalism.' However, as comparative results from the Digital News Report show (Newman, Fletcher, Kalogeropoulos, Levy, \& Nielsen, 2018), individuals in many different countries (US, Spain, Greece, Brazil, etc.) do recognize that they are frequently exposed to disinformation although their interpretation of what exactly this means might differ from academics definition of it. With regard to individuals' capacity to detect disinformation, previous research has been based mostly on cognitive perspectives in order to attempt to distinguish which individuals are more likely to believe fake news or to share this sort of content (Pennycook \& Rand, 2018; Schulz, Werner, \& Müller, 2018). Although results differ greatly depending on the country concerned (Benkler, Faris, \& Roberts, 2018; Humprecht, Esser, \& Van Aelst, 2020), there is a common ground in most of them, defined in previous studies as the 'third person effect' (Jang \& Kim, 2018). This means the widespread belief that 'other people' are the ones who are deceived by fake news rather than oneself or those in one's immediate circle. Age or digital literacy skills are also often cited as predictors of how well or badly individuals might be able to spot fake news, with research often giving different or contradictory results (Jones-Jang, Mortensen, \& Liu, 2019; Pennycook \& Rand, 2018; Wagner \& Boczkowski, 2019).

Taking into consideration the findings of previous research with regard to disinformation as well as the current gap in addressing the gender approach, we will frame our second and third research questions as follows:

RQ2: Are there gender differences in concern about the spread of fake news?

RQ3: Are there gender differences in the perceived degree of difficulty in detecting fake news?

\section{Methodology}

The design of this research is based on a national survey on a sample of $\mathrm{N}=1,001$ Spaniards over 18 years of age. The data were collected by a market research firm (Gesop) through a questionnaire administered online. The sample consisted of 1,001 completed questionnaires, with the sampling stratified by age, sex, autonomous community (Spain is divided into 17 autonomous communities) based on the actual 
distribution of the Spanish population. The margin of sampling error is \pm 3.2 with a $95 \%$ level of confidence and $p=q=0.5$. The fieldwork was carried out from 24-30 April 2019. Table 1 shows the demographics of the participants.

To carry out the research, a broad questionnaire was prepared with five main blocks: sociodemographic data, media consumption, trust in the media, use of social networks, disinformation and social networks. The questions were of two types: with multiple choice single answer or multiple choice. Questions based on a Likert scale (1-7, with 1 being none and 7 a lot) were used in the questions asking participants for their assessment of the proliferation of false news.

For the present investigation, the answers obtained in the following questions have been taken into account: i) Are you concerned about the spread of fake news? ii) Is it difficult for you to identify fake news? iii) How often do you check content you think could be false? iv) What factors do you take into account to assess the reliability of content received on social networks? and v) Which are the most frequent topics of fake news you receive? In addition, we take into account the gender of the respondents and their self-reported use of social networking sites.

The results obtained in these questions were analyzed with the student's test statistic (bilateral), T-test, for independent samples, Chi Square tests were used to verify the existence of dependency relationships between variables. With regard to dependency, the standardized residuals were analyzed. Finally, in those questions with multiple answers, the results were analyzed by comparing proportions for independent samples. The statistic for the significance tests used was the $Z$ (bilateral), in pairwise comparisons. In all cases, the $95 \%$ confidence interval level, which is used in the social sciences, has been used.

\section{Results}

The results obtained show that Spanish people are very concerned about the proliferation of fake news. On a scale of 1 to 7 , with 1 being not at all concerned and 7 being very concerned, the mean obtained is 6.12 $(\bar{x}=6.12, \sigma=1.3)$. Women $(\bar{x}=6.21, \sigma=1.23)$ are significantly more concerned than men $(\bar{x}=6.03, \sigma=1.36)$ regarding fake news dissemination (see Table 2 ).

As Table 3 shows, differences in gender with regard to concern about fake news dissemination does not occur among the youngest, $(\bar{x}=6.06, \sigma=1.36$ in men Vs $\bar{x}=6.10, \sigma=1.14$ among women), nor among the older age group $(\bar{x}=6.18, \sigma=1.25$ in men $\operatorname{Vs} \bar{x}=6.21, \sigma=1.47$ among women). However, it is observed in the 30-59 age range. Despite not being statistically significant it is interesting to see that young men tend to show greater concern than men between 30 and 59. Conversely, among women, concern shows the opposite trend, increasing when participants reach the 30-59 age range.

\subsection{Social Media and Concern about Fake News}

Regarding the analysis of concern about fake news, respondents were divided into two groups, depending on their responses on the Likert scale from 1 to 7 . We considered as 'worried people' those who responded 6 or 7 on the Likert scale, and the unconcerned as those who rated it between 1 and 5 .

The role of social networks as disseminators of disinformation could suggest a certain relationship between their use and individuals' level of concern about fake news. However, it has been observed that the intensity of use of social networks is not correlated with concern about fake news. Only the frequent use of Facebook $\chi^{2}(1, N=791)=5.25, p<.05$ is associated with a high degree of concern. This correlation is not observed

Table 1. Demographics.

\begin{tabular}{llr}
\hline & Response & $\mathrm{N}(\%)$ \\
\hline Gender & Male & $498(49.7 \%)$ \\
& Female & $503(50.3 \%)$ \\
& Total & $1,001(100 \%)$ \\
Age & $16-29$ & $169(16.9 \%)$ \\
& $30-44$ & $310(30.9 \%)$ \\
& $45-59$ & $311(31.0 \%)$ \\
& $\geq 60$ & $211(21.1 \%)$ \\
& Total & $1,001(100 \%)$ \\
\hline
\end{tabular}

Table 2. Concern about fake news dissemination.

\begin{tabular}{lccccccccc}
\hline & 1: Not at all & 2 & 3 & 4 & 5 & 6 & 7: Extremely & Mean & Standard deviation \\
\hline Total & $2.50 \%$ & $0.80 \%$ & $1.90 \%$ & $3.70 \%$ & $11.39 \%$ & $26.87 \%$ & $52.55 \%$ & 6.12 & 1.3 \\
Male & $3.01 \%$ & $0.80 \%$ & $2.01 \%$ & $4.42 \%$ & $12.65 \%$ & $27.51 \%$ & $49.60 \%$ & 6.03 & 1.36 \\
Female & $1.99 \%$ & $0.80 \%$ & $1.79 \%$ & $2.98 \%$ & $10.14 \%$ & $26.24 \%$ & $55.47 \%$ & 6.21 & 1.23 \\
\hline
\end{tabular}


Table 3. Concern about fake news dissemination by gender and age.

\begin{tabular}{|c|c|c|c|c|c|c|}
\hline & \multicolumn{2}{|c|}{$19-29$} & \multicolumn{2}{|c|}{$30-59$} & \multicolumn{2}{|c|}{$60-74$} \\
\hline & $\mathrm{M}$ & $\mathrm{F}$ & M & $\mathrm{F}$ & $M$ & $\mathrm{~F}$ \\
\hline Mean & 6.06 & 6.10 & 5.96 & 6.26 & 6.18 & 6.21 \\
\hline Standard deviation & 1.36 & 1.14 & 1.42 & 1.15 & 1.25 & 1.47 \\
\hline $\mathrm{T}$ test & \multicolumn{2}{|c|}{0.816} & \multicolumn{2}{|c|}{0.008} & \multicolumn{2}{|c|}{0.856} \\
\hline
\end{tabular}

Notes: $p=.05$.

on Twitter and Instagram. The residue analysis confirms the positive correlation between concern and daily use of Facebook.

On analyzing the results obtained from individuals who show higher levels of concern, we can observe the dependency between gender and use of social networks. Women who worry about fake news use Facebook more frequently $\left(\chi^{2}(1, \mathrm{~N}=630)=13.75, \mathrm{p}<.05\right)$ and Instagram $\left(\chi^{2}(1, \mathrm{~N}=424)=4.37, \mathrm{p}<.05\right)$ than worried men; the men who express greater concern about disinformation use Twitter more intensively $\left(\chi^{2}(1, N=334)\right.$ $=8.77, \mathrm{p}<.05)$. The analysis of the standardized residuals confirms the results: Facebook: ( $z$ score $=3.708$ ) and Instagram (z score $=2.091$ ) are used in a greater proportion by women than men, who make more use of Twitter ( $z$ score $=2.962$ ). Among the respondents who stated that they were not concerned, a correlation was detected between daily use and gender in the case of Facebook $\chi^{2}(1, \mathrm{~N}=161)=4.59, \mathrm{p}<.05$; but not on Instagram or Twitter. The specific analysis of the residuals shows that women who are not concerned about fake news make more daily use of Facebook than men who are not concerned ( $\mathrm{z}$ score $=2.14$ ).

Despite these results, it is risky to establish a causal relationship between the two variables, since Facebook $\chi^{2}(1, \mathrm{~N}=791)=19.53, \mathrm{p}<.05$ and Instagram $\chi^{2}$ $(1, N=590)=5.66, p<.05)$ are the social media sites preferred by women, and Twitter $\left(\chi^{2}(1, N=419)=7.10\right.$, $\mathrm{p}<.05)$ is the most popular social network among men.

In conclusion, the intensive use of one or other social network by those who are concerned seems to relate to factors other than fake news, since it reflects the normal behavior in consumption of social media at the gender level.

\subsection{Detecting Fake News}

A majority of respondents (67.13\%) admit to having difficulties in detecting fake news. However, no significant differences can be established between genders $\left(x^{2}(2, \mathrm{~N}=1,001)=1.713, \mathrm{p} .05\right)$.

Nevertheless, the analysis of the difficulty in identifying fake news in relation to the concern for the spreading of fake news allows us to verify the existence of a correlation between the two variables. $76.8 \%$ of concerned citizens report having difficulty in detecting fake news, which drops to $63.58 \%$ among the least worried about its dissemination. Therefore, there is a relationship between concern about the proliferation of fake news and the degree of difficulty in detecting it $\left(\chi^{2}(2, N=998)\right.$ $=14.25, p<.05)$. We can also view it in reverse: Those less concerned about fake news are the same people who claim to have fewer difficulties in detecting it.

At the gender level, in line with previous results, no behavioral differences between men and women were detected. Differences by gender are not statistically significant when it comes to identifying fake news based on individuals' concern about it. Women are more worried than men, but both exhibit the same difficulty in detecting fake news.

The study of trust and credibility is complex and therefore, outside the scope of this article. However, it is known that the tendency to consider a certain content true or false is conditioned by what is accepted as true (Williams, 2002). This is susceptible to change over time and is conditioned by various antecedents and factors such as the characteristics of the message, the sender or the topics (Fulmer \& Gelfand, 2012).

Within this context, research participants were asked what factors they take into account to assess the trustworthiness of the news received through social networks. As it can be seen in Table 4, the source is the most important factor for both men and women, although it is more important for men ( $z$ score $=2,073$ ).

If the degree of concern is taken into account, the results follow a similar pattern. The most concerned participants attach greater importance to the source of the content-the author-(67.3\%) than the less-concerned people $(53.7 \%)$, (z score $=3.6154)$. This behavior is repeated in the analysis at the gender level (men concerned vs. less concerned and women concerned vs. less concerned). Among those who are most concerned, there are no differences between men and women.

Greater concern about the spread of fake news could be related to an increased need for verification. Analysis of the data confirms this point. There is a correlation between the degree of concern about fake news and the frequency of checking it: $\chi^{2}(3, \mathrm{~N}=771)=11.94$, $p<.05$. The most concerned check more frequently, and the least concerned 'almost never.'

Around $42 \%$ of those who are more concerned frequently check ( $z$ score $=2.13$ ), compared to $32.7 \%$ of those less concerned, which results in statistically different values (there is no overlap in the confidence intervals). Those who are least concerned reported almost never checking $(20.1 \%)$, a statistically higher value than 
Table 4. Factors used to assess trustworthiness of news.

\begin{tabular}{lrrlllr}
\hline & $\mathrm{M}$ & $\mathrm{F}$ & Total & $\mathrm{M}(\%)$ & $\mathrm{F}(\%)$ & Total (\%)** \\
\hline Sharer (person who shared the content & 251 & 270 & 521 & 50.40 & 54.00 & 52.20 \\
Source (author of the content) & 337 & 307 & 644 & $67.67^{*}$ & 61.40 & 64.53 \\
Topic & 175 & 191 & 366 & 35.14 & 38.20 & 36.67 \\
Ideological affinity with the content & 96 & 90 & 186 & 19.28 & 18.00 & 18.64 \\
Format & 154 & 149 & 303 & 30.92 & 29.80 & 30.36 \\
Total & 498 & 500 & 998 & & & \\
\hline
\end{tabular}

Notes: ${ }^{*}=$ Statistical difference by gender at $\mathrm{p}=.05 ;{ }^{* *}=$ multi answer question.

$10.6 \%$ of those concerned $(z$ score $=-3.22)$. This behavior does not vary by gender.

\subsection{Topics and Fake News}

Lastly, an analysis was carried out on whether there were gender differences with regard to the fake news topics that the interviewees considered that they have received. Politics is by far the most frequent topic, both among men and women. Statistically significant differences are observed as men receive fake news about politics more frequently ( $z$ score $=2.02$ ). There are no differences regarding the other subjects, except in the case of sport, which is much more frequent among men than among women ( $z$ score $=1.96$ ). Also, there are no differences in the topics received in relation to the degree of concern (see Table 5).

Respondents were asked to cite up to three topics on which they believe they receive fake news most frequently (Table 6). When analyzing the three responses, politics remains the main topic, although does not show any differences between genders. In contrast, nationalism emerges as the second most common topic among men $(42.0 \%)$, a statistically higher percentage than women ( $z$ score $=3.33$ ). Politics, nationalism and immigration are the most common topics for perceived fake news. At a lower level of importance, news about celebrities is also mentioned $(29.4 \%$ of women vs. $22.1 \%$ of men, $z$ score $=-2.64$ ) and sport, significantly more frequently among men than women $(9.4 \%$ vs. $3.4 \%$, $z$ score $=3.89$ ). It was also observed that the degree of concern does not have any relationship with the topic of fake news received.

\section{Conclusion and Discussion}

The main aim of this article is to contribute to the limited existing literature on gender perceptions of fake news. After reviewing the available research on reception, our starting point was to assume that individuals are also 'active' in resisting fake news. Our intention was to analyze whether identified gender differences in news reception, as well as the cognitive costs associated with gender issues in relation to news (Toff \& Palmer, 2019) might have some translation into individuals' perceptions of fake news, and more specifically, with regard to the spread of fake news, the degree of difficulty in detecting it and topics of fake news received.

Our research shows that contrary to what one may expect, there are few differences between genders with regard to disinformation. While in other related matters such as social media use or news consumption, gender differences have been clearly identified, the differences are very subtle on disinformation. The main point is that women are more concerned than men regarding the spread of disinformation which is similar to what happens in other aspects of daily life (i.e., Xiao \& McCright, 2012). However, women and men have similar problems in detecting false content, they use similar factors in assessing trustworthiness, and they receive misleading material about the same topics, mainly politics.

Table 5. Topics and fake news (first response).

\begin{tabular}{lrrrrrr}
\hline & $\mathrm{M}$ & $\mathrm{F}$ & Total & $\mathrm{M}(\%)$ & $\mathrm{F}(\%)$ & Total (\%) \\
\hline Politics & 197 & 167 & 364 & $39.56^{*}$ & 33.53 & 36.47 \\
Immigration & 46 & 64 & 110 & 9.24 & 12.85 & 11.02 \\
Nationalism & 44 & 39 & 83 & 8.84 & 7.83 & 8.32 \\
Science and Technology & 7 & 10 & 17 & 1.41 & 2.01 & 1.70 \\
Feminism/Gender equality & 28 & 25 & 53 & 5.62 & 5.02 & 5.31 \\
Society**/Crime report & 46 & 44 & 90 & 9.24 & 8.84 & 9.02 \\
Sports & 10 & 3 & 13 & $2.01^{*}$ & 0.60 & 1.30 \\
Celebrities & 31 & 46 & 77 & 6.22 & 9.24 & 7.72 \\
DK/NO & 89 & 102 & 191 & 17.87 & 20.48 & 19.14 \\
Total & 498 & 500 & 998 & 100.00 & 100.40 & 100.00 \\
\hline
\end{tabular}

Notes: ${ }^{*}=$ Statistical difference by gender at $\mathrm{p}=.05 ;{ }^{*}=$ includes health, education, and the local news. 
Table 6. Topics and fake news (3 responses).

\begin{tabular}{|c|c|c|c|c|c|c|}
\hline & M & $\mathrm{F}$ & Total & M (\%) & $F(\%)$ & Total $(\%)^{* *}$ \\
\hline Politics & 334 & 316 & 650 & 67.1 & 63.2 & 65.1 \\
\hline Immigration & 182 & 201 & 383 & 36.5 & 40.2 & 38.4 \\
\hline Nationalism & 209 & 159 & 368 & $42.0 *$ & 31.8 & 36.9 \\
\hline Science and Tech. & 38 & 33 & 71 & 7.6 & 6.6 & 7.1 \\
\hline Feminism/Gender equality & 139 & 144 & 283 & 27.9 & 28.8 & 28.4 \\
\hline Society/Crime report & 162 & 162 & 324 & 32.5 & 32.4 & 32.5 \\
\hline Sports & 47 & 17 & 64 & $9.4^{*}$ & 3.4 & 6.4 \\
\hline Celebrities & 110 & 147 & 257 & 22.1 & $29.4^{*}$ & 25.8 \\
\hline DK/NO & 94 & 114 & 208 & 18.9 & 22.8 & 20.8 \\
\hline Total responses & 1,221 & 1,179 & 2,400 & & & \\
\hline Total sample & 498 & 500 & 998 & & & \\
\hline
\end{tabular}

Notes: ${ }^{*}=$ Statistical difference by gender at $\mathrm{p}=.05 ;{ }^{* *}=$ multi answer question.

RQ2 of this research aimed to determine the degree of concern regarding disinformation in Spaniards and whether there are gender differences. In this regard and in line with other research (Eurobarometer, 2018), we can affirm that fake news has become a concern for the Spanish people, women more so than men. It is interesting to observe that the degree of concern does not vary according to gender for young people, which, as a hypothesis and to be explored in future research, could be linked to a higher educational level than previous generations.

The spread of disinformation is closely related to social media use (Tandoc, Lim, \& Ling, 2020), and its use is also related to the degree of concern about the spread of fake news. Our research reveals that Facebook is largely perceived as the leading distributor of fake news both by men and women. Only among the group of the most concerned are any gender-related nuances observed. While women claim that they receive fake news through Facebook and Instagram, men believe it reaches them predominantly through Twitter. However, a causal relationship cannot be established, since various studies clearly show that social networks in Spain show gender differences in user distribution. While Facebook and Instagram are more female, Twitter is largely used by men (We are social, 2020).

In the survey, participants were also asked if they had difficulty distinguishing between false and true information (RQ3). This is a complex issue to address insomuch as it depends on individuals' self-perception as being able to identify false news. It is interesting to note how those who are most concerned about fake news also perceive the greatest difficulty in detecting it, which could suggest that greater awareness of the problem leads to a greater perception of difficulty of detection. Accordingly, those with less concern see themselves as having less difficulty in detecting it. Previous research has shown that individuals have a tendency to consider that the media, and also disinformation, have a greater effect on others than on themselves, in what previous research has identified as the 'third person effect' (Jang \& Kim, 2018). Interestingly, our research shows that most respondents acknowledge that they have problems distinguishing between false and true content, and there are no significant gender differences in this regard either. We do not disregard the 'third person effect,' but we would like to emphasize that, although individuals may believe others are easier to trick, to some extent all of them perceive themselves to be vulnerable to fake news. This issue should be addressed in further research.

As it has been seen, the credibility attached to a particular content is conditioned by multiple factors, relating to the message, to the psychological traits of individuals, or even to the source of the content, which will be subject to change over time and according to the context. Our findings show that these factors apply to both men and women in a very similar way. The only significant gender difference relates to the source (the author of the content), which is more relevant for men. In a classic communication context, this result could be linked to the role that journalism/the media plays in the construction of reality, as well as the fact that men in Spain are more extensive users of news outlets than women (AIMC, 2020). However, in the current hybrid media system, the role of the source goes far beyond the traditional media, which share the stage with new actors, including possible creators and disseminators of false content such as political parties, governments, defenders of conspiracy theorists, etc.

This research allows us to identify two patterns of behavior that go beyond gender: i) Concerned and active users, who are genuinely concerned about fake news, are more aware of the difficulty in detecting it and therefore, make a greater effort to check the veracity of the news they receive; and ii) confident and passive users, who feel less concerned about false news, view is as less difficult to detect and, therefore, they verify the content less and take less account of the source. It would be interesting to verify these typologies in other countries. This correlation between concern and perception of difficulty in detecting disinformation suggest a need to focus more closely on fact-checking processes and results, and foster a questioning attitude towards news. 
Lastly, our RQ1 was to determine whether there are gender differences in the most common topics of fake news that are received. This reflection originates from what previous research has named the 'news consumption gender gap' (Toff \& Palmer, 2019), as it demonstrated significant differences in how women and men find and consume news (Fortunati et al., 2014; Lee, 2013): While women might be more interested in news connected with issues in daily life, men would be more likely to access political news (Poindexter \& Harp, 2008; Rosentiel, 2008). Furthermore, it seems that these differences in news consumption originate from patterns of news avoidance (Toff \& Palmer, 2019). Hence, we believe it was important to see whether these patterns are reproduced in fake news reception. However, the results show that politics-related fake contents are the most common, and that in line with this, perhaps unsurprisingly, politics is, for both men and women, the main topic of the false news they identify. In general, men and women receive false news on similar topics, although politics is clearly the most frequent and the only topic in which significant differences between genders are observed. As we have already seen in earlier literature (AIMC, 2020) men tend to consume more information than women and are more interested in politics. Nevertheless, this is not reflected in a greater ability of men to identify false news, where men and women have the same difficulties.

This research highlights that men, with a greater interest in politics and a greater consumption of news media, have the same difficulties as women in detecting fake news and that this news is on the same topics as women. The greater interest in politics could explain the higher percentage of politics as the first topic mentioned by men. Nationalism also comes into play when the accumulated three topics are considered, this relevance can be explained by the current Catalan-Spanish conflict.

To sum up, previous research has confirmed that men and women exhibit different behavior in relation to news media use, have different interests with regard to news topics, and different social media use. However, the results of this research show that there are no significant gender differences with regard to the ability to detect fake news. Women are more concerned than men, but both have the same problems when facing disinformation content, which has become a widespread global phenomenon today.

\section{Acknowledgments}

This work was supported by the Ministerio de Ciencia, Innovación y Universidades (Spain) RTI2018-095775-BC44 and WhatsApp Misinformation and Social Science Research Awards.

\section{Conflict of Interests}

The authors declare no conflict of interests. This research has been partially funded by WhatsApp Inc. WhatsApp has played no role in directing and conduction the research, nor has had any influence over the authors.

\section{References}

AIMC. (2020). Estudio general de medios: Marco general 2020 [General media study: General framework 2020]. Madrid: Asociación para la Investigación de Medios de Comunicación. Retrieved from www.aimc. es/a1mc-c0nt3nt/uploads/2020/01/marco2020.pdf

Allcott, H., \& Gentzkow, M. (2017). Social media and fake news in the 2016 election. Journal of Economic Perspectives, 31(2), 211-236.

Banaji, S., \& Buckingham, D. (2013). The civic web. Cambridge, MA: MIT Press.

Benesch, C. (2012). An empirical analysis of the gender gap in news consumption. Journal of Media Economics, 25(3), 147-167.

Benkler, Y., Faris, R., \& Roberts, H. (2018). Network propaganda: Manipulation, disinformation, and radicalization in American politics. Oxford: Oxford University Press.

Bird, S. E. (2003). The audience in everyday life: Living in a media world. New York, NY: Routledge.

Boczkowski, P. J. (2010). News at work. Chicago, IL: The University of Chicago Press.

Bond, B. J. (2009). He posted, she posted: Gender differences in self-disclosure on social network sites. Rocky Mountain Communication Review, 6(2), 29-37.

Cai, Z., Fan, X., \& Du, J. (2017). Gender and attitudes toward technology use: A meta-analysis. Computers \& Education, 105, 1-13.

Cavalcante, A., Press, A., \& Sender, K. (2017). Feminist reception studies in a post-audience age: Returning to audiences and everyday life. Feminist Media Studies, 17(1), 1-13.

Chadwick, A. (2013). The hybrid media system. Oxford: Oxford University Press.

Eurobarometer. (2018). Fake news and disinformation online (Flash Eurobarometer No. 464). Brussels: European Commission. Retrieved from https://ec.europa. eu/commfrontoffice/publicopinion

Fortunati, L., Deuze, M., \& de Luca, F. (2014). The new about news: How print, online, free, and mobile coconstruct new audiences in Italy, France, Spain, the UK, and Germany, Journal of Computer-Mediated Communication, 19(2), 1-20.

Fulmer, C. A., \& Gelfand, M. J. (2012). At what level (and in whom) we trust: Trust across multiple organizational levels. Journal of Management, 38(4), 1167-1230.

Guess, A., Nagler, J., \& Tucker, J. (2019). Less than you think: Prevalence and predictors of fake news dissemination on Facebook. Science Advances, 5(1), 2375-2548.

Humprecht, E. (2019). Where 'fake news' flourishes: A comparison across four Western democracies. Information, Communication \& Society, 22(13), 1973-1988. 
Humprecht, E., Esser, F., \& Van Aelst, P. (2020). Resilience to online disinformation: A framework for crossnational comparative research. The International Journal of Press/Politics, 25(3), 493-516.

Jang, S., \& Kim, J. (2018). Third person effects of fake news: Fake news regulation and media literacy interventions. Computer and Human Behavior, 80, 295-302.

Jankowski, N. W. (2018). Researching fake news: A selective examination of empirical studies. Javnost: The Public, 25(1/2), 248-255.

Jenkins, H. (2006). Convergence culture. New York, NY: New York University Press.

Jenkins, H., \& Carpentier, N. (2013). Theorizing participatory intensities: A conversation about participation and politics. Convergence, 19(3), 265-286.

Jones-Jang, S. M., Mortensen, T., \& Liu, J. (2019). Does media literacy help identification of fake news? Information literacy helps, but other literacies don't. American Behavioral Scientist, 65(2). https://doi.org/ 10.1177/0002764219869406

Khaldarova, I., \& Pantti, M. (2016). Fake news. Journalism Practice, 10(7), 891-901.

Lee, A. M. (2013). News audiences revisited: Theorizing the Link between audience motivations and news consumption. Journal of Broadcasting \& Electronic Media, 57(3), 300-317.

Livingstone, S. (1998). Audience research at the crossroads: The 'implied audience' in media and cultural theory. European Journal of Cultural Studies, 1(2), 193-217.

Masip, P., Aran-Ramspott, S., Ruiz-Caballero, C., Suau, J., Almenar, E., \& Puertas-Graell, D. (2020). Consumo informativo y cobertura mediática durante el confinamiento por el Covid-19: Sobreinformación, sesgo ideológico y sensacionalismo [News consumption and media coverage during the confinement by Covid-19: Information overload, ideological bias and sensationalism]. El Profesional de la Información, 29(3).

Mattelart, A., \& Neveu, E. (2003). Introducción a los estudios culturales [Introduction to cultural studies]. Barcelona: Paidós.

Morley, D. (1992). Television, audiences and cultural studies. London: Routledge.

Mourão, R. R., \& Robertson, C. T. (2019). Fake news as discursive integration: An analysis of sites that publish false, misleading, hyperpartisan and sensational information. Journalism Studies, 20(14), 2077-2095.

Mudde, C. (2019). The far right today. Cambridge: Polity Press.

Newman, N., Fletcher, R., Kalogeropoulos, A., Levy, D. A. L., \& Nielsen, R. K. (2018). Reuters Institute digital news report 2018. Oxford: Reuters Institute for the Study of Journalism. Retrieved from http://media.digitalnewsreport.org/wp-content/ uploads/2018/06/digital-news-report-2018.pdf

Nielsen, R. K., \& Graves, L. (2017). 'News you don't believe': Audience perspectives on fake news. Reuters Institute. Retrieved from https:// reutersinstitute.politics.ox.ac.uk/our-research/ news-you-dont-believe-audience-perspectives-fakenews

Pennycook, G., \& Rand, D. G. (2018). Who falls for fake news? The roles of bullshit receptivity, overclaiming, familiarity, and analytic thinking. Journal of Personality. https://doi-org.proxy.library.upenn. edu/10.1111/jopy.12476

Poindexter, P., \& Harp, D. (2008). The softer side of news. In P. Poindexter, S. Meraz, \& A. S. Weiss (Eds.), Women, men and news: Divided and disconnected in the news media landscape (pp. 85-96). New York, NY: Routledge.

Renau, V., Carbonell, X., \& Oberst, U. (2012). Redes sociales on-line, género y construcción del self [On-line social networks, gender and construction of the self]. Revista de Psicologia, Ciències de l'Educació i de l'Esport, 30(2), 97-107.

Rosentiel, T. (2008). Where men and women differ in following the news. Pew Research Center. Retrieved from http://www.pewresearch.org/2008/02/06/ where-men-and-women-differ-in-following-thenews

Salaverría, R., Buslón, N., López-Pan, F., León, B., LópezGoñi, I., \& Erviti, M. C. (2020). Desinformación en tiempos de pandemia: Tipología de los bulos sobre la Covid-19 [Disinformation in times of pandemic: Typology of hoaxes on Covid-19]. El Profesional de la Información, 29(3).

Schulz, A., Werner, W., \& Müller, P. (2018). We are the people and you are fake news: A social identity approach to populist individuals' false consensus and hostile media perceptions. Communication Research, $12,1-26$.

Scolari, C. (2012). Media ecology: Exploring the metaphor to expand the theory. Communication Theory, 22(2), 204-225.

Stabile, B., Grant, A., Purohit, H., \& Harris, K. (2019). Sex, lies, and stereotypes: Gendered implications of fake news for women in politics. Public Integrity, 21(5), 491-502.

Ştefăniţă, O., Corbu, N., \& Buturoiu, R. (2018). Fake news and the third-person effect: They are more influenced than me and you. Journal of Media Research, 11(3), 5-23.

Tandoc, E. C., Lim, D., \& Ling, R. (2020). Diffusion of disinformation: How social media users respond to fake news and why. Journalism, 21(3), 381-398.

Tandoc, E. C., Lim, Z. W., \& Ling, R. (2018). Defining 'fake news.' Digital Journalism, 6(2), 137-153.

Toff, B., \& Palmer, R. A. (2019). Explaining the gender gap in news avoidance: 'News-is-for-men' perceptions and the burdens of caretaking. Journalism Studies, 20(11), 1563-1579.

Tucker, J. A., Guess, A., Barbera, P., Vaccari, C., Siegel, A., Sanovich, S., . . Nyhan, B. (2018). Social media, 
political polarization, and political disinformation: A review of the scientific literature. Menlo Park, CA: Hewlett Foundation. Retrieved from https://www.hewlett.org/wp-content/uploads/ 2018/03/Social-Media-Political-Polarization-andPolitical-Disinformation-Literature-Review.pdf

Wagner, M. C., \& Boczkowski, P. J. (2019). The reception of fake news: The interpretations and practices that shape the consumption of perceived misinformation. Digital Journalism, 7(7), 870-885.

Wardle, C., \& Derakhshan, H. (2017). Information disorder: Towards and interdisciplinary framework for research and policy making (Report No. 09). Stras- bourg: Council of Europe. Retrieved from https://rm. coe.int/information-disorder-toward-an-inter disciplinary-framework-for-researc/168076277c

We are social. (2020). Digital: 2020 Spain. We are Social. Retrieved from https://wearesocial.com/es/digital2020-espana

Williams, B. (2002). Truth and truthfulness. Princeton, NJ: Princeton University Press.

Xiao, C., \& McCright, A. M. (2012). Explaining gender differences in concern about environmental problems in the United States. Society \& Natural Resources, 25(11), 1067-1084.

\section{About the Authors}

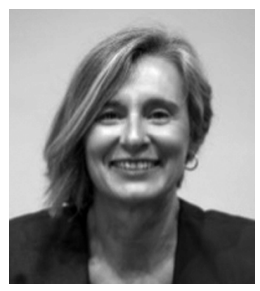

Ester Almenar is a Lecturer at the School of Communication and International Relations of the Ramon Llull University. She holds a PhD degree in Communication. Her areas of expertise are marketing and business strategy. She is a Member of the Digilab research group and her research interests are the impact of uncertainty on customers, news' consumption and trust on news.

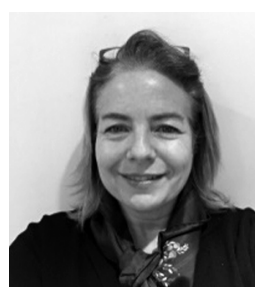

Sue Aran-Ramspott is Associated Professor at the School of Communication and International Relations at the Ramon Llull University. Her areas of expertise are the relationship between public and media narratives and ethics of the audiovisual fictional representations. Currently, as a Member of Digilab, she leads a research project funded by the Spanish Ministry of Science, Innovation and Universities 'TeensMediaLife' She is the PhD Communication Program Coordinator.

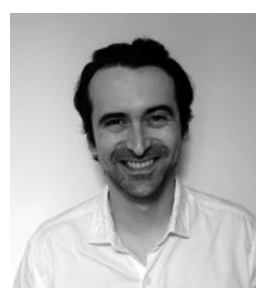

Jaume Suau has a PhD in Communication and is a lecturer at Ramon Llull University, based in Barcelona. As a member of Digilab research group has been Project Manager of the MedMedia, being a member also of the Media Pluralism Monitor, all projects funded by the European Commission. His research interests are audience studies, news' consumption and trust on news, as well as media regulation and media development.

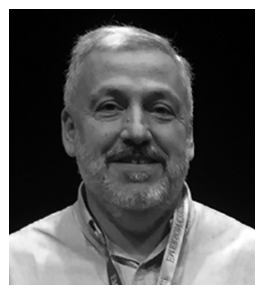

Pere Masip is Associate Professor at the School of Communication and International Relations Blanquerna at the Ramon Llull University (Barcelona, Catalonia). His research interests center on the impact of technology on journalistic and communication practices. He has participated in several national and international projects. He is currently coordinating a research project funded by the Spanish Ministry of Science, Innovation and Universities 'News Consumption, Social Networks and Pluralism in the Hybrid Media System.' 